\title{
Late attendance of maternal health care services: A Nepalese context
}

\author{
Rameswor Baral* \\ Lecturer, Department of Population Studies, Tribhuvan University, Prithivi Narayan Campus, Pokhara, Nepal
}

\begin{abstract}
This article is trying to attempt that the Nepalese maternal health care services, its associated concepts, situation and tries to find out the factors influencing for late attending it. Small changes to the system will result in small results; the changes need to be sustained over a very long period, even after the change is detected. It will be changed by strict monitoring and healthy feedback system can revive the whole system. Reducing MMR and fertility are remains a key health challenges in Nepal. Drastic changes will appear within a couple of years, strategic planning will illustrate how your current system is affected and will be affected by the change to improve the health care services and to reach the desired goal. Improving the quality of health services is difficult a well important issue in Nepal. The Government should involve and operate the only way is increasing public private partnership at each level of health care will be helpful. More efforts should be given to educating society in general and mothers in particular, to strengthen community participation and to increase the accessibility of reproductive health care services. Moreover, providing accurate information about the services provided in the health institutions is required from the concerned GOs and NGOs.
\end{abstract}

\section{General background}

"Reproductive health is a state of complete physical, mental, social well-being and not merely the absence of disease or infirmity, in all matters relating to the reproductive system in its functions and processes". It implies that people are able to have a satisfying and safe sexual life and that they have the capability to reproduce and the free to decide if, when and how often to do so. Implicit in this last condition are the right of men and women to be informed and to have access to safe, effective, affordable and acceptable methods of family planning of their choice, as well as other methods of birth control which are not against the law, and the right of access to appropriate healthcare services that will enable women to go safely through pregnancy (maternal) and childbirth and provide couples with the best chance of having a healthy infant [1]. Late attendance means barriers associated with to the delays on leading to most pregnancy-related health care of women to benefit from life-saving interventions these are as follows:

- Delayed decision to seek medical care

- Delay of getting to the health center

- Delay of receiving adequate care when a facility is reached

- Lack of proper Post-partum follow-up, etc

The relationship between population and development is keeping with this new focus on reproductive health, the ICPD focused on the needs of people as opposed to setting demographic targets. At the end of the conference, the member states produced a consensus document called the Program of Action (POA), which sets forth goals to be achieved over a period of twenty years (1994-2014). Although the POA is an expression of political will and does not constitute international law, it outlines the priorities of the states parties and indicates the commitment on their part to work toward achieving them.

High population growth created challenge in many societies and led to a global movement of birth control, soon with the active involvement of national governments. This movement can be dated to the about 1950s, with events such countries have adopted the first population policy [2]. Reproductive health issues are growing health concerns in the South Asian region and around the world. Many factors affect reproductive health, including diet, activity level, age, stress, and pharmaceutical use. These issues are important for health care providers because studies demonstrate that health care would be dramatically improved, and medical care costs reduced if environmental pollution and exposure to chemicals were reduced. An increased awareness of the effects of environmental contaminants on patient health will allow health care providers to offer more timely and appropriate care, to better understand potential causes of reproductive problems, to better track and study reproductive outcomes, and to protect patients from preventable harm.

Globally, some 550,000 pregnancy-related deaths occur every year, 90 percent of which are in developing countries. MMR is the main factor that substantially lowers the life expectancy of women. Twenty-five per cent of maternal deaths occur during pregnancy; 50 percent within 24 hours of childbirth; 20 percent within seven days of delivery; and 5 percent from two to six weeks after childbirth [3]. The health of mothers has long been acknowledged to be a cornerstone of public health. However, as the 20th anniversary of the launch of the Global Safe Motherhood Initiative (GSMI) by the WHO is upon us, the global burden of maternal mortality and morbidity remains essentially

Correspondence to: Rameswor Baral, Lecturer, Department of Population Studies, Tribhuvan University, Prithivi Narayan Campus, Pokhara, Nepal, E-mail: rameswor_baral@yahoo.com

Key words: family planning, late attendance, MDGs, Nepal, maternal health, women

Received: January 30, 2018; Accepted: February 26, 2018; Published: March 02,2018 
unchanged. Maternal mortality represents the health indicator with the greatest disparity between developed and developing countries. The WHO estimates that over 300 million women suffer from illness brought about by pregnancy and childbirth and that 5, 15,000 women die each year from pregnancy-related causes [3] and the trend of MMR of the world has decreased from 269 to 136 per 1,00,000 live birth [4]. Shockingly, almost all of these, 99 percent, occur in developing countries [5]. Fortunately, the WHO also estimates that more than 80 percent of maternal deaths can be prevented or avoided through actions that are proven effective and affordable, even in developing countries. The three core strategies are comprehensive reproductive health services including family planning and safe abortions; skilled care for all women at childbirth by a qualified midwife, nurse or doctor and emergency obstetric care for women with complications [6].

\section{Methods and materials}

The article is reviewing the situation of Nepalese maternal health care as compared to the two decades of the country. The article is based on secondary data of different national level demographic and health surveys of Nepal at a different period and contemporary references. It combines the different data from 1996-2016 AD and tries to analyze its trends, scenarios and socio-economic differences in late utilization of maternal health care and fertility regulation of Nepalese women. This article is trying to analyze and state the factors association of situation and causes of late utilization of maternal health services in Nepal.

\section{Result and discussion}

Nepal is a low-income country with the total population of 26.49 million. The reproductive health status of women and girls, especially ethnic groups who live in the remote areas remains poor. Nepal had one of the highest maternal mortality rates $(281 / 100,000$ live birth) compared to its neighboring countries according to the Nepal Demographic Health Survey, 2011.The total fertility rate was 2.6 children per woman aged 15-49 years old. In rural areas, women and adolescent girls have a shorter interval between births; many young women have a higher fertility rate compared to those living in the urban areas [7]. According to MDGs, Nepal should struggle for significant reductions in maternal mortality by the year 2015: a reduction in MMR was 539/100,000 live births in 1996, before the legalization of safe abortion, 50 percent of all maternal deaths were due to abortion related complications. The latest MMR is $281 / 100,000$ and Nepal's target is to reduce MMR to 134 by the end of 2015 [4].

Maternal health is not a concern about a country; it is a global issue in this time. The country has had adopted population and introduced reproductive health policies and the program has controlled their maternal and infants' death. Finally, we know that it is possible. Success stories abound, even in poor countries, of efforts that have been able to decrease maternal deaths. When societies cannot deliver for women, women's ability to deliver for themselves, their children, families, and societies are hampered. When investments in women lag, the economic cost of maternal death and disability is significant, and so is the opportunity cost for nations in terms of lost possibilities for achieving social and economic development. The lack of progress is especially of concern for South Asia and sub-Saharan Africa, which has consistently experienced the worst maternal health rates in the world. It is no coincidence that these regions also lag in progress on a range of broader development outcomes, including poverty reduction and the status of women [8] (Figure 1).

In order to Nepal achieve the MDGs 5 of reducing maternal mortality three quarters (MDG 5) by 2015 requires 181 women per

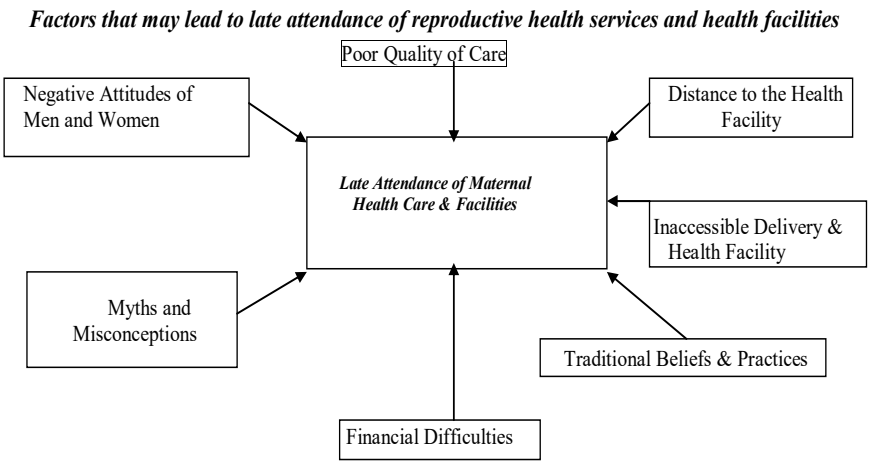

Source: K. Josephine and A. Christine, 2000

Figure 1. Factors that may lead to late attendance of reproductive health services and health facilities

100000 live births reductions of maternal mortality. However, the actual reduction of Nepal between 1990 and 790 and it is 190 at 2015 [4]. This slow progress in reducing maternal mortality is as a result of a number of factors including late attendance of reproductive and maternal health care services. Globally, low in maternal health care services remains a problem to health care providers and policy makers. Since, the ICPD conference and the Beijing conference, only 58 percent of the total women give a lot of emphases to encourage male involvement in reproductive health including maternal health. The Beijing conference emphasized that man's attitudes, knowledge base and ways of reacting influences not only men's health but also women's reproductive health.

Those women with low level of education, women married to husbands with the low level of education, women who are unemployed and engaged with fields and traditional works women who reside in rural areas were attained lately in utilizing maternal health care services. Thus, improving the education of the population in general women in particular and availing appropriate package of maternal services to the target groups could be an appropriate strategy to the utilization of maternal health care services in such the area. Expansion of maternal health services and facilities also increases accessibility of programs of fertility control. Maternal health care services in Nepal are heavily subsidized by government, fertility control services are provided at low cost. The South East Asian countries have wide disparities in socioeconomic and health indicators. This region accounts for almost one-third of global mortality in neonates and children under 5 years of age, and many countries in this region are unlikely to attain MDGs 4 and 5. Although maternal and child mortality is on the decline in South East Asia, there are still major disparities, and greater equity is key to achieve the MDGs and SDGs [9]. There is wide discrimination on, inequality and disparity in socioeconomic and health status among the countries. More than one-third of maternal and child deaths of global mortality occur in this region. Many countries in this region are unlikely to attain MDGs 4 and 5, even though maternal child health is the priority agenda of all the countries of this region.

The MMR rate in Nepal is among the moderate in South Asian region. The Nepal Demographic and Health Survey, at 2011, it was 281 deaths of women per 100,000 live births with the figures in the rural areas being higher than in the urban centers. Maternal mortality can be reduced by women reporting early for ante natal care and reporting for delivery at the health facility. There is a positive trend of increase in knowledge of women about ante natal care, the importance of receiving ante natal care early and the pregnancy complications during the two (1994-2015) decades. The negative attitude towards health facility and health workers is slowly changing among the reproductive population in Nepal (Table 1). 
Table 1. Percentage and trends in maternal health care, Nepal, 2001-2016

\begin{tabular}{|l|c|c|c|c|}
\hline \multirow{2}{*}{ Maternal Health Care/Indicators } & \multicolumn{4}{|c|}{ Year } \\
\cline { 2 - 5 } & 2001 & 2006 & 2011 & 2016 \\
\hline ANC by a skilled provider & 28 & 44 & 58 & 84 \\
\hline Birth occurred in a health facility & 9 & 18 & 35 & 57 \\
\hline Birth attended by a skilled provider & 11 & 19 & 36 & 58 \\
\hline All vaccines & 66 & 83 & 87 & 78 \\
\hline TFR (Per Women) & 4.1 & 3.8 & 2.6 & 2.3 \\
\hline
\end{tabular}

Source: MOHP, 2002, 2007, 2012, 2016 Key Indicators Report, MOHP, Nepal

There has been a steady improvement in the maternal health care indicators over the past 15 years. Among women receiving ANC from a skilled provider, the percentage increased from 28 percent in 2001 to 84 percent in 2016. Similar improvement in the percentage of births delivered at a health facility has been witnessed, with an increase from 9 percent to 57 percent. Also, the percentage of births attended by skilled providers increased from 11 percent to 58percent over the same period [7]. The government of Nepal has set a long-term target of reducing fertility to the replacement level by the end of the 12th plan (20132017) and achieving MDGs 5 for Nepal to reducing the late attendance of reproductive health services i.e. providing such facilities to micro area and covered to targeted women of reproductive age experience high fertility at an early age. More than 80 percent of maternal deaths can be prevented or avoided through actions that are proven effective and affordable, even in developing countries [3].

About millions of women suffer from lasting complications such as fistulae, prolepses, inability in controlling urination, or painful intercourse. The services most often linked to the reduction of maternal morbidity include antenatal care during pregnancy, tetanus vaccination, professional child delivery (including emergency services access), postnatal care and family planning services. Those women with low level of education, women married to husbands with the low level of education, women who are unemployed and engaged with fields and traditional works women who reside in rural areas were attained lately in utilizing maternal health care services. A woman with an unhealthy reproductive system may suffer from various pregnancies related complications. These are some of the major causes of mortality in women and child. Early marriage, a common problem in Nepal, also contributes to the deterioration of women's reproductive health. Women in Nepal get married at a fairly young age, lately attaining for checking such health facilities, because of early marriage; they get pregnant earlier and are likely to bear more children. To keep the reproductive health problems at bay and other problems to get rid of reproductive health problems as they are also some of the causes for deteriorating health in women [10].

Public health nurses must remain active in the prevention of avoidable pregnancy related death and illness. Through the delivery of effective interventions, monitoring and evaluation and organized advocacy we can mobilize resources and generate the political will to make maternal health a priority. The three core strategies are comprehensive reproductive health services including family planning and safe abortions; skilled care for all women at childbirth by a qualified midwife, nurse or doctor and emergency obstetric care for women with complications [6].

\section{Conclusion}

Nepalese reproductive health care service is appearing to be poor. High MMR represents that the failure of health care system to effectively provide services and care for women and the failure of society to keep women in good health. High rates of MMR and IMR are continuing to be important challenges for Nepalese health systems as mothers become pregnant each year are expected to develop complications. Thus, improving the level of education of the target group and availing appropriate package of maternal services for fast utilization of maternal health care services in such the area. Early marriage practices are very common in Nepal. Many of them are far away from the reproductive health education because of early marriage they start bearing baby which causes high IMR, MMR and resulting high fertility among them is so high, which are affecting the demographic indicators of the country.

The GoN has to adopt the strategic plan is done every 5 years to determine the goals and objectives are met according to the mission and vision of SDGs for improving the quality of reproductive health care service begins with the evaluation of internal and external environment of the health care delivery system. Identify and analyze the reproductive health care needs and available health care services. Assessment will provide accurate and sufficient data that will serve as a basis for the quality of health care services. Formulate parameters are to evaluate the implementation of health care services for those women who are marginalized, unemployed and engaged with fields and traditional works and residing in rural areas were attained lately in utilizing maternal health care services. Thus, improving the education of the population in general women in particular and availing appropriate package of maternal services to the target groups could be an appropriate strategy to the utilization of maternal health care services in such the area.

While there are many important barriers to improving maternal health services; such as access, quality, and cost of care-adequate investment in maternal health is an essential first step to addressing them all. Today, still, millions of women reproductive aged cannot use or late attendance of maternal health services because they have to pay for them at the time they receive them, and many of those who do use services suffer financial hardship or are even impoverished because they have to pay. More than half a million women lose their lives in the process of reproduction worldwide every year and most of these mortalities are avoidable if mothers have access to maternal health care services [3]. Women in all age groups had a poorer experience of maternity services in Nepal. That this was still the case following the publication of a number of national policy documents and local initiatives to improve childbirth experiences and outcomes for women is a cause for concern.

There is an urgent need to think, to research and to plan ahead of the challenges of serving proper health services. Increasing the level of women's education and awareness then it should directly positive effects on their reproductive behavior i.e. ANC, during delivery and PNC. Thus, reproductive health care services of Nepal must be reengineering and taking into account the growing need for more investment, much more care for the forthcoming mothers too. Among several challenges, it seems keys to transfer health care services directly to the social daily working spaces/institutions, etc. There is a lot of scope for enhancing healthcare service in government owned healthcare set ups in Nepal. The easiest and cheapest way is to revise the reproductive health services program and the processes those form of these serves. Finally, we know that it is possible. Success stories abound, even in poor countries, like Nepal, of efforts that have been able to decrease maternal deaths. Egypt, Honduras, Malaysia, Sri Lanka, Thailand and parts of Bangladesh all halved the number of maternal deaths over the last several decades, some over much shorter time periods. What is common in all these is political commitment and effective health inputs. Their experiences suggest that with the right commitment and 
investment, MDGs and SDGs 5 is achievable [11]. It is emphasizing that the importance of the proper understanding and use of the term in international negotiations. Strategic planning will illustrate how your current system is affected and will be affected by the change to improve the health care services and to reach the desired goal. Strategic planning will illustrate how you will respond to change. Improving the quality of health services is difficult as the well important issue in Nepal. The government should involve and operate the only way is increasing public private partnership (PPP) at each level of health care will be helpful [12-20].

\section{Reference}

1. United Nation (1994) Report of the International Conference on Population and Development. (ICPD) Cairo, Egypt

2. Sinding SW (2007) Overview and perspective. In: Warren C. Robinson and John A. Ross (eds.), The Global Family Planning Revolution, Three Decades and Policies and Programs, World Bank, Washington, DC, pp: 1-10.

3. World Health Organization (2014) Maternal Mortality. Fact Sheet. No. 348, New York. http://www.who.int/mediacentre/factsheets/fs348/en/

4. Population Reference Bureau (2015) World Population Data Sheet 2015. PRB

5. Menken J, Duffy L, Kuhn R (2003) Childbearing and Women's Survival: New Evidence from Rural Bangladesh. Population \& Development Review 29: 405-426.

6. Freedman LP, Graham WJ, Brazier E, Smith JM, Ensor T, et al. (2007) Practical Lessons from Global Safe Motherhood Initiatives: Time for a New Focus on Implementation. Lancet 370: 1383-1391

7. Ministry of Health, Nepal; New ERA; and ICF (2017) Nepal Demographic and Health Survey 2016: Key Indicators. Kathmandu, Nepal: Ministry of Health, Nepal.
8. World Bank (2004) Round II Country Reports on Health, Nutrition, and Population Conditions Among the Poor and the Better-Off in 56 Countries.

9. Ross L, Simkhada P, Smith WC (2005) Evaluating Effectiveness of Complex Interventions Aimed at Reducing Maternal Mortality in Developing Countries. Journal of Public Health 27: 331-337.

10. Bist JC (2016) The Himalayan Times. April 26, Kathmandu, Nepal.

11. United Nations (2015) We Can End Poverty: Millennium Development Goals and Beyond 2015. Goal 5 Improve Maternal Health. http://www.un.org/millenniumgoals/ maternal.html

12. Finlayson K, Downe S (2013) Why Do Women Not Use Antenatal Services in Lowand Middle-Income Countries? A Meta-Synthesis of Qualitative Studies. PLOS Medicine 10: 1-12.

13. Hoyert DL (2007) Maternal Mortality and Related Concepts. Vital Health Stat 3: 1-13. [Crossref]

14. Knudsen L (2006) Reproductive Rights in a Global Context.

15. Pan American Health Organization (2010) A Historical Review of Its Contributions to Health, Health Care, and Health Policies 1962-2008. (PAHO) Advisory Committee on Health Research, WHO; Geneva.

16. Reher DS (2011) Economic and Social Implications of the Demographic Transition Population and Development Review 37: 11-33.

17. Sandra L (1994) Population Control to Reproductive Health: An Emerging Policy Agenda. Social Science and Medicine 39: 993.

18. World Health Organization (2004) Beyond the Numbers: Reviewing Maternal Deaths and Complications to Make Pregnancy Safer. (WHO); Geneva.

19. World Health Organization (2004) Maternal Mortality in 2000: WHO; Geneva.

20. World Health Organization (2006) Reproductive Health Indicators: Guidelines for Their Generation and Analysis for Global Monitoring. WHO; Geneva.

Copyright: (C2018 Baral R. This is an open-access article distributed under the terms of the Creative Commons Attribution License, which permits unrestricted use, distribution, and reproduction in any medium, provided the original author and source are credited. 